\title{
Parâmetros anátomo-estruturais de orgãos reprodutivos de ovinos sem raça definida (SRD) nativos do Estado da Paraíba, com e sem bipartição escrotal: estudo do escroto e funículo espermático ${ }^{1}$
}

\author{
Mikael L.D.L. Tolentino ${ }^{2 *}$, Laura H. Oliveira² ${ }^{2}$ Otávio B. Sousa ${ }^{2}$, Antonio A.N. \\ Machado Júnior ${ }^{3}$, Antonio C. de Assis Neto ${ }^{4}$, Maria A.M. de Carvalho ${ }^{5}$ \\ e Danilo J.A. Menezes ${ }^{2}$
}

\begin{abstract}
Tolentino M.L.D.L., Oliveira L.H., Sousa O.B., Machado Júnior A.A.N., Assis Neto A.C., Carvalho M.A.M. \& Menezes D.J.A. 2014 [Anatomical and structural parameters of reproductive organs of crossbred rams native from the state of Paraíba, Brazil, with and without scrotal bipartition: study of the scrotal skin and spermatic cord.] Parâmetros anátomo-estruturais de órgãos reprodutivos de ovinos sem raça definida (SRD) nativos do estado da Paraíba, com e sem bipartição escrotal: estudo de pele escrotal e funículo espermático. Pesquisa Veterinária Brasileira 34(7):709-715. Área de Morfofisiología, Unidade Acadêmica de Medicina Veterinária, Universidade Federal de Campina Grande, Av. Universitária s/n, Patos, PB 58700-970, Brazil. E-mail: mikaeltolentino@gmail.com

Forty-two crossbred rams were used, divided according to their scrotal configuration. Twelve of these animals were used to investigate the testicular biometry and scrotal skin histology. The other animals were used to study the spermatic cord. The animals were placed in a group of 21 animals without scrotal bipartition (GEI) and another with scrotal bipartition (GEII) which did not reach 50\% of the length of the scrotum's longitudinal axis. In each group, scrotal skin fragments from six rams and spermatic cord fragments from 5 others were collected, processed by routine histological tests and analyzed with a microscope. In 10 rams latex was injected into the testicular artery to obtain vascular molds and the artery length. Comparison of groups GEI and GEII showed no significant statistical differences $(p<0.05)$ between scrotal thickness (epidermis and dermis), histological constituency of the scrotal skin, number of sudoriferous glands per area, scrotal bipartition length or testicular biometric parameters. However, the total length of the testicular arteries of GEI was greater than of GEII $(p<0.05)$. It was concluded from the morphological parameters analyzed that scrotal bipartition in rams did not influence the skin structure, scrotal bipartition or testicular biometry when compared with animals that did not present this characteristic. Further studies should be carried out to elucidate the appearance of this characteristic in rams and whether it is desirable or not for improved production of these animals in warm climate regions.
\end{abstract}

INDEX TERMS: Scrotal partition, sudoriferous glands, scrotal skin, reproduction., rams.

\footnotetext{
${ }^{1}$ Recebido em 2 de janeiro de 2014.

Aceito para publicação em 9 de abril de 2014.

${ }^{2}$ Unidade Acadêmica de Medicina Veterinária, Centro de Saúde e Tecnologia Rural (CSTR), Universidade Federal de Campina Grande (UFCG), Avenida Universitária s/n, Patos, PB 58700-970, Brasil. *Autor para correspondência: mikaeltolentino@gmail.com

${ }^{3}$ Universidade Federal do Piauí (UFPI), Campus Profa Cinobelina Elvas, Planalto Cibrazen, Bom Jesus, PI 64900-000, Brasil.

${ }^{4}$ Faculdade de Medicina Veterinária e Zootecnia, Universidade de São Paulo (USP), Av. Prof. Dr. Orlando Marques de Paiva 87, Cidade Universitária, São Paulo, SP 05508270, Brasil.

${ }^{5}$ Departamento de Morfofisiologia Veterinária, Centro de Ciências Agrárias, UFPI, Campus Ministro Petrônio Portela, Socopo, Teresina, PI 64049550, Brasil.
}

RESUMO.- Foram utilizados 42 ovinos sem raça definida, divididos segundo a configuração escrotal. Destes animais, 12 foram utilizados na investigação da biometria testicular e histologia da pele escrotal. Os demais foram destinados ao estudo do funículo espermático. Os animais foram agrupados em um grupo de 21 animais sem bipartição escrotal (GEI) e 21 com bipartição escrotal, (GEII), esta não atingindo $50 \%$ do comprimento do eixo longitudinal do escroto. Em cada grupo, em 6 animais foram coletados fragmentos da pele do escroto e em 5 do funículo espermáticos, e processados em rotina histológica e analisados em microscopia de luz; e em 10 foram injetados látex na artéria testicular 
para obtenção de moldes vasculares e obtenção do comprimento da artéria. Quando comparados os grupos GEI e GEII, não foram encontradas diferenças estatísticas significativas $(p<0,05)$ entre a espessura do escroto (epiderme e derme), constituição histológica da pele escrotal, número de glândulas sudoríparas por área, comprimento do funículo espermático ou parâmetros biométricos testiculares. Entretanto, o comprimento total das artérias testiculares do GEI foi maior do que o GEII $(p<0,05)$. Concluiu-se, com base nos parâmetros morfológicos analisados, que a bipartição escrotal em ovinos não influenciou na estrutura da pele, funículo ou biometria testicular quando comparado aos animais que não apresentavam esta característica. Outros estudos merecem atenção para desmistificar o porquê do aparecimento dessa característica em ovinos e se esta característica é ou não desejável para melhoria na produção desses animais em regiões de clima quente.

TERMOS DE INDEXAÇÃO: Bipartição escrotal, glândulas sudoríparas, tegumento escrotal, reprodução, carneiros.

\section{INTRODUÇÃO}

Com um rebanho efetivo de 9,3 milhões de cabeças, o nordeste brasileiro possui o maior rebanho ovino entre as regiões do país (Guimarães Filho 2010), apesar do clima quente e seco do nordeste, o que reforça a importância de estudos que venham a possibilitar um maior desenvolvimento produtivo da espécie para esta região em particular(Leite \& Simplício 2009).

Estudos demonstram o aparecimento de uma caracteristica nos órgãos reprodutores em caprinos, denominada de bipartição escrotal, a qual está presente em animais criados próximo da linha do equador, em regiões de temperaturas elevadas (Robertshaw 1982, Nunes et al. 1984). Esta característica anatômica também foi observada na espécie ovina criada em regiões com tais características (Melo et al. 2011). Possivelmente a bipartição escrotal pode ser indício de que os animais que a apresentam são mais adaptados às regiões semiáridas, uma vez que nos caprinos com esta característica é sugerido uma maior facilidade para equilibrar a produção de espermatozóides em altas temperaturas(Nunes et al. 1984, Pascualy \& Eloy 1985). Reforçando esta teoria, pesquisas demonstram que caprinos com bipartição escrotal apresentam maior produção espermática diária (Machado Júnior et al. em 2011) e maior número de células germinativas e de Sertoli por secção de tubulos seminíferos (Machado Júnior et al. 2012), quando comparado com caprinos sem bipartição.

Segundo a literatura (Nunes et al. 1983a, Silva et al. 1986), a bipartição aumenta a superfície de contato do escroto e testículo com o meio externo, contribuindo desta forma para uma termorregulação mais eficaz do calor nessa região. Estudos referentes a bipartição escrotal têm sido feito na espécie caprina e comprovado que a bipartição é desejada em reprodutores desta espécie devendo ser considerada a divisão do escroto como critério de seleção de reprodutores superiores em clima tropical, pois animais com essa característica apresentam sêmen de melhor qualidade (Almeida et al 2010).
O escroto é um divertículo abdominal que tem a função de proteger os testículos e colaborar com o mecanismo de termorregulação por meio do seu fluxo sanguíneo, de trocas calóricas e da sudorese (Kastelic et al. 2000). A epiderme deste órgão é composta por epitélio estratificado pavimentoso queratinizado (Dellmann \& Brown 1982, Banks 1992, Gartner \& Hiatt 1993, Schaller 1999, Frandson et al. 2005), a qual é formado pelos estratos basal ou germinativo, espinhoso, granuloso, lúcido e córneo; (Dellmann \& Brown 1982, Banks 1992, Gartner \& Hiatt 1993, Schaller 1999) com espessura variando de acordo com a região do escroto (Dellmann \& Brown 1982, Banks 1992). A derme é composta de tecido conjuntivo frouxo e pouco tecido adiposo (Dellman \& Brown 1982, Banks 1992) e é dotada de uma camada de glândulas sudoríparas adrenérgicas (Hafez \& Hafez 2004). Estas glândulas podem chegar a produzir cinco vezes mais suor que as de outras partes do corpo, dependendo do grau de elevação da temperatura corporal (Robertshaw \& Vercoe 1980). Além destas estruturas, a localização dos testículos no interior desta bolsa é fator fundamental para a espermatogênese, uma vez que a temperatura no seu interior corresponde de $2^{\circ} \mathrm{C}$ a $6^{\circ} \mathrm{C}$ abaixo da temperatura abdominal (Setchell 1978).

A termorregulação também é garantida pela conformação do funículo espermático. Esta estrutura é composta pela artéria testicular, veia testicular que forma o plexo pampiniforme, vasos linfáticos, plexo testicular de nervos autônomos, ducto deferente, feixe de tecido muscular liso e lâmina visceral da túnica vaginal (Köning 2004). Ocorre íntima relação entre artéria e veia testicular, o que proporciona um eficiente mecanismo de contracorrente de perda de calor, através do qual o sangue arterial que chega aos testículos cede calor ao sangue venoso que sai deste órgão (Getty 1986, Dyce 1997, Hafez 2004, Köning 2004).

$\mathrm{Na}$ busca por animais mais adaptados as condições adversas do semiárido, e considerando a importância dos componentes estruturais do escroto e do funículo espermático para o mecanismo de termorregulação testicular, aliado a carência de informações sobre as influência da bipartição escrotal sobre estas estruturas em ovinos, objetivou-se com esse trabalho avaliar os aspectos histológicos da pele escrotal, por meio de sua análise estrutural, e avaliar a composição morfológica do funículo espermático de ovinos com ou sem bipartição escrotal e correlacionar tais resultados com a biometria testicular dos grupos pesquisados.

\section{MATERIAL E MÉTODOS}

As coletas foram realizadas no abatedouro público do Município de Patos - PB, Microrregião de Patos do Sertão paraibano.

Foram utilizados 42 ovinos SRD divididos segundo a configuração escrotal (21 animais GEI - grupo de animais com escroto sem bipartição e 21 animais GEII - grupo de ovinos com bipartição escrotal). Destes animais, 12 animais foram utilizados na investigação da biometria testicular e dos parâmetros escrotais. Os demais foram destinados ao estudo do funículo espermático. 0 trabalho foi aprovado pelo Comitê de Ética da Universidade Federal de Campina Grande ( № 14, 2011)

Para o estudo histológico da pele do escroto, após o abate dos animais, utilizou-se um vazador do tipo "Punch" para cole- 
ta dos fragmentos transversais da pele escrotal de 12 animais experimentais ( 6 animais do grupo GEI e 6 do grupo GEII) com aproximadamente $1 \mathrm{~cm}$ de diâmetro, dos terços proximal, médio e distal das faces cranial e caudal(nos animais sem escroto bipartido) e proximal, médio e medial da rafe escrotal (nos animais com escroto bipartido). As amostras foram fixadas em formaldeído a $10 \%$ tamponado onde permaneceram por 48 horas. Após a coleta dos fragmentos escrotais, os testículos foram pesados separadamente e tiveram seus eixos testiculares maiores e menores determinados através da utilização de Paquímetro. Passada às 48 horas de fixação, os fragmentos de escroto foram submetidos ao processamento histológico e cortados a $5 \mu \mathrm{m}$ de espessura. De cada fragmento foram obtidos 2 cortes não consecutivos, os quais foram corados pelo método da hematoxilina-eosina. Foram realizadas mensurações da espessura da epiderme e derme. Para cada corte, foram feitas 10 medições da espessura da epiderme e derme, de forma sequencial e paralela. Posteriormente foram feitas as quantificações das glândulas sudoríparas por corte analisado. Para mensuração da epiderme e derme, e também para quantificação das glândulas sudoríparas foi utilizado o Sistema de Análise de Imagem (Image Pro-Express v.6.0), com escala micrométrica, e acoplado ao microscópio de luz, marca Olympus BX40, utilizandose objetiva de $20 \mathrm{x}$.

No estudo do funículo espermático foram utilizados 10 animais para analise histológica dos componentes estruturais e 20 animais para medição do comprimento da artéria testicular. Em 5 animais de cada grupo (bipartido e não bipartido), o funículo espermático de cada testículo foi isolado e posteriormente cortado transversalmente nas regiões proximal, medial e distal. Foram fixados em Formol a $10 \%$ por um período de 24 horas. Seguida a fixação, o material foi submetido a lavagem em água corrente por 24 horas e acondicionado em álcool a 70\%. Posteriormente o material foi processado em rotina histológica convencional com impregnação em parafina para obtenção de cortes com $5 \mu \mathrm{m}$ de espessura, que foram corados pelo método da hematoxilina-eosina. 0 material foi analisado em microscópio de luz (Olympus BX40) por meio do Sistema de Análise de Imagem (Image Pro-Express v.6.0).

Para determinar o comprimento da artéria testicular, os funículos foram perfundidos com látex corado (bi-centrifugado-Cis-I-4) do ânulo inguinal até a cabeça do epidídimo. As artérias testiculares foram isoladas e posteriormente submetidas à corrosão em água, por um período de oito dias, para a obtenção dos moldes. Os moldes vasculares foram então postos em um suporte de madeira de $90 \mathrm{~cm}$ de comprimento contendo uma fenda longitudinal de aproximadamente $3 \mathrm{~mm}$ de largura, evitando-se distensão do molde, e estes foram medidos com auxílio de fita métrica.

Os resultados obtidos foram submetidos à análise de variância pelo programa estatístico BioEstat 5.0 e tiveram seus valores médios comparados pelo teste de ANOVA com critério a 5\% de probabilidade.

\section{RESULTADOS}

O escroto dos ovinos apresentaram características macroscópicas normais, sem alterações externas e sem evidencia de aderências internas. A bipartição não atingia 50\% do comprimento do eixo longitudinal do escroto (Fig.1). Nesses animais, os testículos eram menores e mais largos do que naqueles que não apresentavam bipartição (Quadro 1). Microscopicamente a pele escrotal era constituída por epiderme, derme e hipoderme.

A partir da região proximal até a região distal, a epiderme do escroto apresentou uma diminuição progressiva de sua espessura (Fig.2). A derme era constituída por tecido

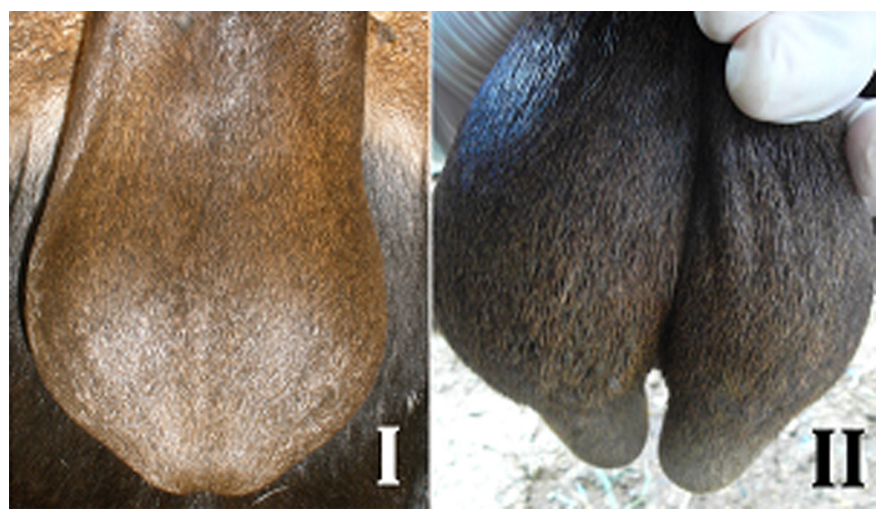

Fig.1. Escroto de ovinos SRD. Animal sem escroto bipartido (GEI) e animal com escroto bipartido (GEII).

Quadro 1. Médias e desvio padrão dos eixos testiculares maiores e menores e pesos testiculares absolutos dos ovinos com e sem bipartição escrotal

\begin{tabular}{lcc}
\hline Parâmetros & \multicolumn{2}{c}{ Grupos } \\
\cline { 2 - 3 } & GEI & GEII \\
\hline Eixo maior $(\mathrm{cm})$ & $9,18 \pm 0,92^{\mathrm{a}}$ & $6,94 \pm 0,95^{\mathrm{a}}$ \\
Eixo menor $(\mathrm{cm})$ & $5,40 \pm 0,80^{\mathrm{a}}$ & $4,28 \pm 0,95^{\mathrm{a}}$ \\
Peso testicular $(\mathrm{g})$ & $110,66 \pm 33,16^{\mathrm{a}}$ & $126,66 \pm 41,45^{\mathrm{a}}$
\end{tabular}

Médias seguidas de mesma letra na linha não diferem estatisticamente pelo teste t de studant a 5\% de significância.

conjuntivo frouxo, pouco tecido adiposo, um conjunto de glândulas sudoríparas, algumas glândulas sebáceas e folículos pilosos (Fig.2). Os folículos pilosos atravessavam a epiderme e se projetava para o meio externo. Na base dos folículos pilosos foram observadas glândulas sebáceas

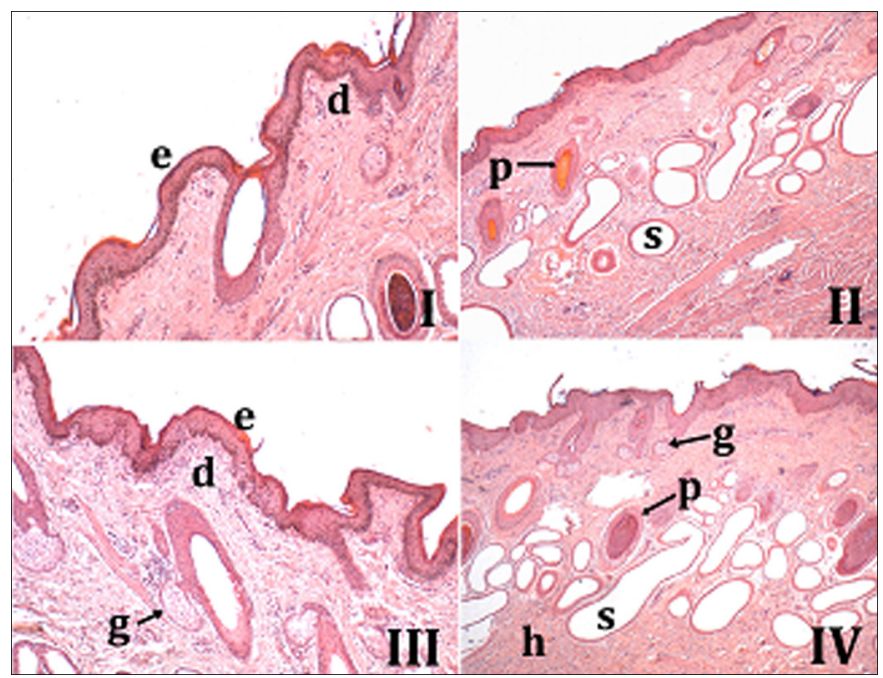

Fig.2. Parede do escroto de ovinos SRD, com e sem bipartição escrotal. (I) Região caudal proximal do escroto não bipartido de ovinos revelando epiderme bem definida (e), com queratina e derme subepitelial (d) com evidência de glândulas sudoríparas e folículos pilosos. HE, obj.20x. (II) Região caudal distal do escroto bipartido de ovinos apresentando vários folículos pilosos (p) e glândulas sudoríparas subepiteliais (s). HE, obj.20x. (III) Região crâniomedial do escroto não bipartido de ovinos revelando a epiderme (e) mais espessa, derme (d) com folículos pilosos, glândulas sudoríparas e sebáceas (g). HE, obj.20x. (IV) Região crâniodistal do escroto bipartido de ovinos apresentando vários folículos pilosos (p), glândulas sudoríparas (s) e sebáceas (g); além do tecido conjuntivo da hipoderme (h). HE, obj.20x. 
Quadro 2. Valores médios e desvio padrão da espessura do escroto (Epiderme e Derme), densidade numérica das glândulas sudoríparas por área analisada em escroto de ovinos com e sem bipartição escrotal

\begin{tabular}{|c|c|c|c|c|c|c|}
\hline \multirow{2}{*}{$\begin{array}{l}\text { Região/ } \\
\text { Grupos }\end{array}$} & \multicolumn{2}{|c|}{ Proximal (Cranial/Caudal) } & \multicolumn{2}{|c|}{ Média (Cranial/Caudal) } & \multicolumn{2}{|c|}{ Distal/Rafe (Cranial/Caudal) } \\
\hline & GEI & GEII & GEI & GEII & GEI & GEII \\
\hline & & & $227+14$ & & $145,07 \pm 21,18^{\mathrm{a}}$ & \\
\hline & $3,81^{\mathrm{a}}$ & 1055 & $1187,56 \pm$ & 1092,7 & $1076,82 \pm$ & $8,37^{\mathrm{a}}$ \\
\hline QGSA $(\mu \mathrm{m} 2)$ & $49 \pm 15,92^{\mathrm{a}}$ & $44,75 \pm 8,84^{\mathrm{a}}$ & $55 \pm 13,56^{\mathrm{a}}$ & $44 \pm 2,42^{\mathrm{a}}$ & $57 \pm 16,98^{\mathrm{a}}$ & $54,66 \pm 14,02^{\mathrm{a}}$ \\
\hline
\end{tabular}

EEPI = espessura da epiderme, EDER = espessura da derme QGSA = quantidade de glândulas sudoríparas por área. Médias seguidas de mesma letra na linha não diferem estatisticamente pelo teste t de studant a $5 \%$ de significância.

(Fig.2) que possuíam características histológicas de glândulas acinosas simples. As glândulas sudoríparas do escroto apresentavam-se como estruturas tubulosas simples e enoveladas do tipo apócrinas.

Quando comparados os grupos GEI e GEII, não foram encontradas diferenças significantes entre a espessura do escroto (epiderme e derme), na sua face cranial e caudal, e no número de glândulas sudoríparas por área, entre os animais com bipartição escrotal em comparação àqueles sem bipartição escrotal (Quadro 2).

0 funículo espermático dos ovinos, independente da conformação do escroto, apresentava disposição anatômica típica. No interior do funículo espermático foi observada uma artéria testicular, inicialmente retilínea, espiralando-se em todo o comprimento do funículo. Os giros aumentavam, em número, da região proximal à distal (Fig.3). Uma veia testicular, com disposição característica, constituindo o plexo pampiniforme ao redor da artéria. Na face mediocaudal do funículo espermático, ligado e acompanhando toda a sua extensão, observava-se o mesoducto deferente, sustentando o ducto deferente, suas artérias e veias.

Histologicamente, o funículo espermático mostrou-se circundado por um epitélio pavimentoso simples (mesotélio), apoiado em uma fina camada de tecido conjuntivo denso não modelado, formando a lâmina parietal da túnica vaginal, seguido de tecido conjuntivo frouxo contendo vasos submesoteliais. Os espaços intervasculares do funículo eram preenchidos por tecido conjuntivo frouxo intimamente ligado à adventícia das artérias e veias (Fig.4).

Nos cortes histológicos da artéria testicular foi possível observar a camada interna, composta pelo endotélio vascular e a lâmina limitante elástica interna, dando aspecto pregueado à mucosa; a túnica média formada por uma espessa camada de músculo liso e a túnica externa composta por tecido conjuntivo frouxo. Foi observada a veia testicular desprovidas de válvulas, desde a parte proximal do funículo espermático até sua porção distal, e apresentando múltiplas secções vasculares cheios de sangue, dando aspecto de várias veias, formando o plexo denominado de plexo pampiniforme (Fig.4).

Quanto à morfometria, os resultados obtidos para o comprimento do funículo espermático estão expressos no Quadro 3, na qual observamos que não houve diferença estatística significativa $(p>0,05)$ entre os animais estudados. Quando comparamos o comprimento dos funículos esquerdos dos Grupos I e II, assim como os funículos direitos dos respectivos grupos, obtivemos dados de média e desvio pa- drão do GI maiores do que no GII, no entanto esta diferença não foi significativa $(p>0,05)$. Analisando os animais do GI e comparando seus antímeros, foi possível chegar a conclusão de que o antímero esquerdo obteve valores maiores do

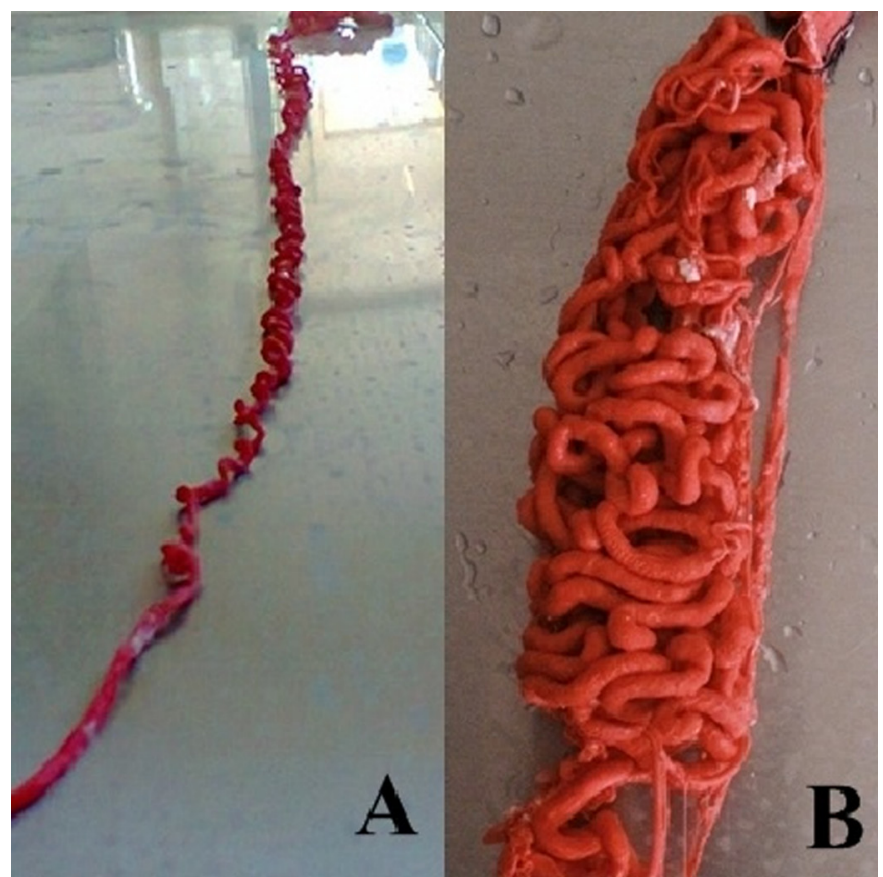

Fig.3. Moldes vasculares em látex da artéria testicular de ovinos SRD. (A) Artéria testicular estendida para mensuração e (B) Artéria testicular em posição anatômica no funículo espermático, mostrando-se gradativamente mais convoluta de proximal para distal.

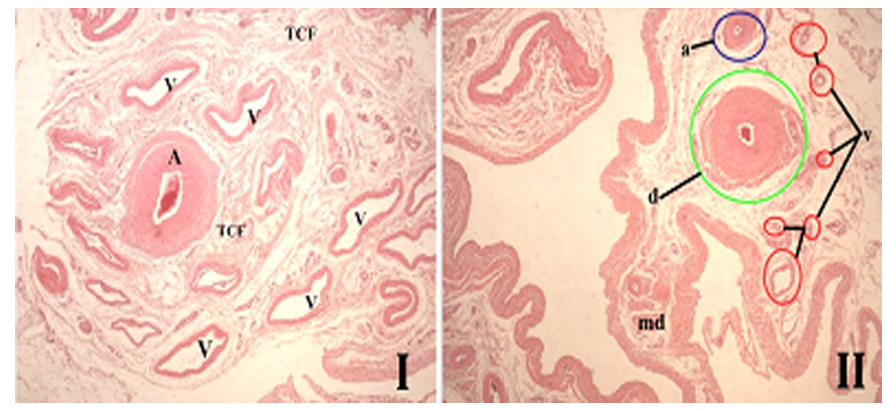

Fig.4. Funículo espermático de ovino SRD com escroto bipartido. (I) Evidencia-se artéria testicular (A), veias do plexo pampiniforme (V) e tecido conjuntivo frouxo (TCF) sustentando os componentes do funículo. HE, obj.4x. (II) Nota-se o ducto deferente (d) e mesoducto deferente (md), demonstrando conformação clássica, a artéria epididimária (a) e veias (v). HE, obj.4x. 


\section{Quadro 3. Valores morfométricos (média + desvio padrão) do funículo espermático em ovinos nos diferentes grupos estudados}

\begin{tabular}{lcc}
\hline \multirow{2}{*}{ Funículo espermático } & \multicolumn{2}{c}{ Grupos } \\
\cline { 2 - 3 } & GEI & GEII \\
\hline Comprimento direito $(\mathrm{cm})$ & $7,80+0,62^{\mathrm{a}}$ & $7,35+0,56^{\mathrm{a}}$ \\
Comprimento esquerdo $(\mathrm{cm})$ & $8,01+0,56^{\mathrm{a}}$ & $7,64+0,43^{\mathrm{a}}$
\end{tabular}

Médias seguidas de mesma letra na mesma coluna ou linha, não diferem estatisticamente pelo teste SNK a 5\% de significância.

que o direito, assim como aconteceu na comparação de antímeros do GII, o que também não foi significativo $(p>0,5)$.

0 ducto deferente mostrou-se com formato circular em secção transversal, apresentando lume irregular com mucosa pregueada e presença de espermatozóide no seu lume (Fig.4). A mucosa do ducto deferente, com epitélio do tipo pseudoestratificado prismático, estava apoiada em camada muscular média dupla de músculo liso, com uma camada circular interna e outra longitudinal externa. Uma terceira camada envolvendo o ducto deferente estava representada por uma serosa denominada de mesoducto deferente, apresentando uma camada serosa externa formada por epitélio pavimentoso simples (mesotélio) e uma camada fibrosa interna de tecido conjuntivo denso não modelado, apoiado em tecido conjuntivo frouxo contendo vasos sanguíneos subcapsulares. 0 mesoducto deferente, era formado por duas camadas mesoteliais apoiadas em tecido conjuntivo denso não modelado, unidas uma a outra por tecido conjuntivo frouxo contendo vasos sanguíneos (Fig.4).

Os dados obtidos sobre o comprimento da artéria testicular (Quadro 4) foram comparados entre antímeros e pôde-se observar, apesar de não significativa $(p>0,5)$, que tanto no GI quanto no GII o antímero esquerdo mostrou valores maiores que o direito. Referente ao comprimento total das artérias testiculares, no GI foi maior do que no GII $(\mathrm{p}<0,05)$.

\section{Quadro 4. Comprimento médio e desvio padrão da artéria testicular de ovinos nos diferentes grupos estudados}

\begin{tabular}{lcc}
\hline \multirow{2}{*}{ Funículo espermático } & \multicolumn{2}{c}{ Grupos } \\
\cline { 2 - 3 } & GEI & GEII \\
\hline Comprimento direito $(\mathrm{cm})$ & $119,7+0,62^{\text {ab }}$ & $102,1+0,56^{\mathrm{b}}$ \\
Comprimento esquerdo $(\mathrm{cm})$ & $126,5+0,56^{\mathrm{a}}$ & $110,3+0,43^{\mathrm{ab}}$ \\
Total & $123,10+20,57^{\mathrm{a}}$ & $106,20+14,85^{\mathrm{b}}$
\end{tabular}

Médias seguidas de mesma letra na mesma coluna ou linha, não diferem estatisticamente pelo teste SNK a 5\% de significância.

\section{DISCUSSÃO}

A biometria testicular nos ovinos SRD não apresentou diferenças significantes entre os grupos avaliados. Tomando-se por base que as medidas biométricas refletem na capacidade dos testículos em produzir espermatozoides (Mies Filho 1987, Martins Filho \& Lobo 1991, Bittencourt et al. 2003, Guimarães et al. 2003) pode-se inferir que reprodutores da espécie ovina portadores de bipartição escrotal, quando comparados com os reprodutores de escroto não bipartidos, não evidenciam características testiculares que justifique alterações ou prejuízos para a capacidade reprodutiva destes animais. Havendo, inclusive, uma composição tegumentar semelhante, o que indica uma equivalência de condições para dissipação do calor no escroto, e sugere a ocorrência de condições similares de termorregulação.

A constituição histológica do escroto dos ovinos é semelhante à descrita para caprinos, porém, nos ovinos não há diferença entre a espessura do escroto e do número de glândulas sudoríparas quando comparados os animais bipartidos e não bipartidos. Diferentemente dos dados apresentados para reprodutores caprinos que, segundo (Nunes et al. 2010), os animais com bipartição escrotal apresentam uma epiderme mais espessa e uma maior quantidade de glândulas sudoríparas, indicando com isso uma maior produção de suor no escroto que consequentemente irá propiciar a estes animais uma melhor termorregulação testicular.

Conforme descrito por Nickel et al. (1979), Getty (1986) e Dyce et al. (1997), o funículo espermático dos ovinos estudados apresentava conformação típica dos mamíferos, revelando forma cônica, estendendo-se desde o anel inguinal até a extremidade capitada do testículo. Também como descrito para caprinos da raça Bhuj (Costa 1987), ovinos deslanados (Borelli et al. 1989) e ovinos da raça Corriedale (Carvalhal et al. 2000), no interior do funículo espermático de ovinos observava-se a artéria testicular, inicialmente retilínea, tornando-se espiralada em todo o comprimento do funículo e a veia testicular, com disposição característica, constituindo o plexo pampiniforme ao redor da artéria, o que foi, independende da configuração escrotal, semelhante ao descrito em caprinos (Nunes et al. 2013).

Na face medialcaudal do funículo espermático dos ovinos observou-se o mesoducto deferente sustentando suas artérias e veias, ligando e acompanhando toda a sua extensão, coincidindo com descrições de Nickel et al. (1979), Godinho et al. (1981), Getty(1986), Barone (1996), Dyce et al. (1997), Schaller (1999) e Nunes (2005) para os ruminantes e Nunes et al. (2013) para caprinos com diferentes graus de bipartição escrotal.

Quanto à análise histológica, foi possível observar no funículo espremático de ovinos uma constituição padrão estabelecida para os pequenos ruminantes (Nickel et al. 1979, Costa 1987, Machado et al. 1996, Carvalhal et al. 2000, Nunes, 2013), com tecido conjuntivo submesotelial e intervascular, mostrando-se como material de sustentação para as estruturas componentes do funículo espermático.

Células adiposas foram encontradas na camada de tecido conjuntivo frouxo do funículo espermático de ovinos, em maior quantidade na região distal, conforme ocorre em caprinos (Nunes et al. 2013), e que não se diferenciava conforme a configuração escrotal (bipartido e não bipartido), diferente do relatado pelo autor para caprinos, o qual observou diferenças nas disposições e quantidades de tecido adiposo dependendo do grau de bipartição escrotal. Apesar da importância do tecido adiposo como isolante térmico, é provável que este componente conjuntivo não interfira na termorregulação do testículo, já que, segundo Carvalhal et al. (2000) as células adiposas não exercem esta função no funículo espermático de caprinos por não envolver todo o funículo, entretanto, Machado Júnior et al. (2009) observaram que, no período do ano de temperaturas mais elevadas, 
os caprinos com escroto bipartido mantinham a temperatura escroto-testicular menor que os caprinos sem bipartição, o que Nunes et al. (2013) inferiu que provavelmente o tecido adiposo impediu a entrada da temperatura ambiente para o funículo espermático.

Foram vistas secções da artéria testicular nos sentidos transversal e longitudinal do funículo espermático, conforme descrito em caprinos da raça Bhuj (Costa 1987) e os ovinos da raça Corriedale (Carvalhal et al. 2000), onde a estrutura histológica da artéria testicular revelou uma camada interna, composta de endotélio vascular e uma lâmina limitante elástica interna; uma camada média e uma camada externa de tecido conjuntivo frouxo. Esta composição microscópica foi semelhante para os funículos do grupo bipartido e não bipartido, conforme descrito em caprinos com e sem bipartição escrotal (Nunes et al. 2013).

A parede das veias do plexo pampiniforme era forrada internamente por um endotélio vascular, apoiado numa fina camada de tecido conjuntivo frouxo, que se segue por uma camada média de músculo liso mais delgada do que a observada na parede da artéria testicular. A camada externa dos vasos do plexo, de tecido conjuntivo frouxo, muitas vezes mostrava-se delgada, dando íntima aproximação destes vasos com a artéria testicular, similar ao descrito em Costa (1987) e Machado et al. (1996).

As características morfológicas do ducto deferente não diferiram das apresentadas por (Nickel et al. 1979, Godinho et al. 1981, Costa 1987, Borelli et al. 1989, Barone 1996, Dyce et al. 1997), quando afirmam que o órgão apresenta formato circular, mucosa revestida por epitélio pseudoestratificado prismático, apoiada sobre uma camada de músculo liso e outra camada denominada mesoducto deferente circundando o ducto, sendo esta formada por uma camada externa de epitélio pavimentoso simples e uma camada interna de tecido conjuntivo denso não modelado apoiado em tecido conjuntivo frouxo contendo vasos sanguíneos.

No que se refere ao comprimento da artéria testicular presente no funículo espermático, nos animais dos dois grupos, as médias apresentadas para o comprimento da artéria foram inferiores ao encontrado na literatura, em pequenos ruminantes (Costa 1987, Borelli et al. 1989, Carvalhal et al. 2000). 0 comprimento total das artérias testiculares dos ovinos estudados foi maior no grupo não bipartido do que no grupo bipartido, diferente de caprinos, onde os animais com maior grau de bipartição escrotal apresentavam artérias testiculares maiores quando comparados aos de menor grau de bipartição e não bipartidos (Nunes et al., 2013).

Os dados morfométricos do escroto de ovinos se comportaram de forma diferente aos encontrados para caprinos. Nestes animais verificou-se que na bipartição escrotal, a média dos dados morfométricos era maior do que aqueles sem bipartição (Nunes 2005). Podemos relacionar essa diferença ao fato de alguns caprinos possuírem mais de $50 \%$ do escroto bipartido e nos ovinos estudados a bipartição não ultrapassa os 50\%, sendo um indício de evolução e adaptação dos animais ao clima quente (Nunes 1983b). Outra hipótese é que essa diferença pode está relacionado ao fato da existência de uma maior área para dissipação de calor do escroto, consequentemente haverá uma menor necessidade de troca de calor entre a artéria e a veia, entendendo-se dessa maneira que o organismo pode está compensando a eficiência da perda de calor, pela maior superfície de contato do escroto, com menor comprimento de artéria testicular. Estudos mais aprofundados devem ser realizados para validar uma ou outra hipótese.

\section{CONCLUSÃO}

Com base no exposto conclui-se que, apesar da bipartição escrotal apresentar-se em ovinos, diferente do que foi observado em caprinos, esta modificação não acarreta alterações significantes nas características morfológicas do funículo espermático, pele escrotal ou biometria testicular, sugerindo não ocorrer prejuízos ou benefícos a sua funcionalidade. Entretanto, tendo em vista que não foram encontrados ovinos com bipartição escrotal que chegasse a $50 \%$ do comprimento do testículo, outros estudos carecem ser realizados que apontem se há ou não diferenças funcionais resultantes da bipartição escrotal nesta espécie.

Agradecimentos.- Ao Conselho Nacional de Desenvolvimento Científico e Tecnológico (CNPq) pela bolsa de pesquisa e ao Abatedouro Municiapal de Patos, PB, pela doação do material deste trabalho.

\section{REFERÊNCIAS}

Almeida M.M., Machado Júnior A.A.N., Ambrósio C.E., Menezes D.J.A., Righi D.A.I. Nascimento M.R. \& Carvalho M.A.M. 2010. Influência do grau de bipartição escrotal sobre parâmetros reprodutivos de caprinos. Pesq. Vet. Bras. 30(4):345-350

Bank W.J. 1992. Histologia Veterinária Aplicada. 2ª ed. Manole, São Paulo. 658p.

Barone R. 1996. Anatomie comparée des mammifères domestiques: Angiologie. Vigot, Paris. 904 p.

Bittencourt R.F., Ribeiro Filho A.L. \& Almeida A.K. 2003. Avaliação de carneiros da raça Santa Inês baseando-se na circunferência escrotal. Revta Bras. Reprod. Anim. 27(2):195-197.

Borelli V., Bombonato P.P. \& Rodrigues C.A. 1989. Contribution of the spermatic cord in ovine. Anais XIII Federative International Congress, Rio de Janeiro, RJ, p.67.

Carvalhal R., Borelli V. \& Miglino M.A. 2000. Estudo morfológico do funículo espermático em ovinos da raça Corriedale (Ovis aries L., 1758). Braz. J. Vet. Res. Anim. Sci. 37(5):348-354.

Costa L.A.O.P. 1987. Contribuição ao estudo do funículo espermático em caprinos da raça Bhuj Brasileira. Dissertação de Mestrado em Anatomia Animal, Faculdade de Medicina Veterinária e Zootecnia, Universidade de São Paulo, São Paulo, SP. 45p.

Dellman H.D. \& Brown E.M. 1982. Histologia Veterinária. Guanabara Koogan, Rio de Janeiro. 397p.

Dyce K.M., Sack W.O. \& Wensing C.J.G. 1997. Tratado de Anatomia Veterinária. $2^{a}$ ed. Guanabara Koogan, Rio de Janeiro. 663p.

Frandson R.D., Wilke L.W. \& Fails A.D. 2005. Anatomia e Fisiologia dos Animais Domésticos. 6⿳a ed. Guanabara Koogan, Rio de Janeiro. 454p.

Gartner L.P. \& Hiatt J.L. 1993. Atlas de Histologia. Guanabara Koogan, Rio de Janeiro. 322p.

Getty R. 1986. Sisson/Grossman Anatomia dos Animais Domésticos. Vol.1. $5^{\underline{a}}$ ed. Guanabara Koogan, Rio de Janeiro. 1134 p.

Godinho H.P., Cardoso F.M. \& Nascimento J.F. 1981. Anatomia dos Ruminantes Domésticos. Departamento de Morfologia, Instituto de Ciências Biológicas da UFMG, Belo Horizonte. 415p.

Guimarães Filho C. 2010. Guia do Educador: manejo básico de ovinos e caprinos. Sebrae, Brasília. 148p. 
Guimarães J.D., Vasconcelos C.O.P., Guimarães S.E.F., Costa E.P., Neto T.M. \& Dias F. 2003. Biometria testicular em bovinos da raça Nelore, dos 20 aos 22 meses de idade. Revta Bras. Reprod. Anim. 27(2):173-174.

Hafez E.S.E. \& Hafez B. 2004. Reprodução Animal. 7ạ ed. Manole, Barueri. 513p.

Kastelic J.P., Cook R.B. \& Coulter G.H. 2000. Scrotal/testicular thermoregulation in bulls. In: Chenoweth P.J. (Ed.), Topics in Bull Fertility. International Veterinary Information Service. Disponível em <http://www.ivis. org>

König H.E. \& Liebich H.G. 2004. Anatomia dos Animais Domésticos: texto e atlas colorido. Vol.2. Artmed, Porto Alegre. 400p.

Leite E.R. \& Simplício A.A. 2009. Importância Econômica da Produção de Caprinos e Ovinos no Nordeste Brasileiro. Disponível em <http://www. cnpc.embrapa.br/importancia.htm>.

Machado Júnior A.A.N., Miglino M.A., Menezes D.J.A., Assis Neto A.C., Leiser R., Silva R.A.B. \& Carvalho M.A.M. 2009. Influence of the bipartite scrotum on the testicular and scrotal temperatures in goats. Pesq. Vet. Bras. 29(10):797-802.

Machado Júnior A.A.N., Assis Neto A.C., Ambrósio C.E., Leiser R., Lima G.S., Oliveira L.S. \& Carvalho M.A.M. 2011. Goat scrotal-testicular biometry: Influence of the season on scrotal bipartition. Pesq. Vet. Bras. 31(11):1116-1119.

Machado Júnior A.A.N., Oliveira L.S., Assis Neto A.C., Alves F.R., Miglino M.A. \& Carvalho M.A.M. 2012. Spermatogenesis in goats with and without scrotum bipartition. Anim. Reprod. Sci. 130(1):42-50.

Machado M.R.F., Borelli V., Miglino M.A. \& Passipieri M. 1996. Contribution to the Study of the Funiculus spermaticus in Murrah Buffaloes (Bubalus bubalis Linnaeus, 1978). Braz. J. Morphol. Sci. 13(1):7-13.

Martins Filho R. \& Lôbo R.B. 1991. Circunferência escrotal como critério de seleção em bovinos, tendo em vista o melhoramento de características reprodutivas em ambos os sexos. Ciênc. Anim. 1(2):83-91.

Melo T.M.V., Lima Filho J.A.C., Silva J.G., Amaral C.R.A., Correia F.R., Sampaio M.O., Vasconcelos N.C.T., Souza W.M.A. \& Coelho M.C.O.C. 2011. Testículos bipartidos em ovinos morada nova: relato de caso. Anais XIX Congresso Brasileiro de Reprodução Animal, Recife, PE, p.306.
Mies Filho A. 1987. Reprodução dos Animais. 6ª ed. Livraria Sulina, Porto Alegre. 314p.

Nickel R., Schummer A. \& Seiferle E. 1979. The Viscera of the Domestic Mammals. $2^{\text {nd }}$ ed. Paul Parey, Berlin. 401p.

Nunes A.S. 2005. Morfologia do funículo espermático e do escroto em caprinos, nativos do estado do Piauí, com diferentes configurações escrotais. Dissertação de Mestrado em Ciência Animal, Centro de Ciências Agrárias, Universidade Federal do Piauí, Teresina, PI. 61p.

Nunes J.F., Riera G.S., Silva A.E.F.D., Ponce de Leon F.A. \& Lima F.A.M. 1983a. Características espermáticas de caprinos Moxotó de acordo com a morfologia escrotal. Embrapa Capínos, Sobral, CE. 11p.

Nunes J.F., Silva A.E.D.F., Riera S.G., Lima F.A.M. \& Ponce de Leon F.A. 1983b. Report on observed differences in goat semen characteristics based on scrotal morphology. Reunion Internacionale de Reproduction des Ruminants en Zone Tropical, Guadelupe. INRA, Paris, 1984, p.251-264.

Nunes A.S., Filho M.F.C., Machado Júnior A.A.N., Abreu-Silva A.L., Conde Júnior M.A., Souza J.A.T. \& Carvalho M.A.M. 2010. Descrição histológica do escroto de caprinos nativos do estado do Piauí segundo o grau de bipartição escrotal. Ciência Rural 40(8):1808-1813.

Nunes A.S., Carvalho M.A.M., Conde Junior A.M., Ferraz M.S. \& Machado Júnior A.A.N. 2013. características morfológicas do funículo espermático de caprinos com escroto bipartido e não bipartido. Ciênc. Anim. Bras. 14(3):338-344.

Pascualy O.S. \& Eloy A.X. 1985. Evaluacion de parametros reproductivos en machos ovinos y caprinos. Embrapa Caprinos, Sobral, CE. 1985.

Robertshaw D. 1982. Concepts in Animal Adaptation: thermoregulation of the goat. International Conference on Goat Production and Disease. Dairy Goat Journal, Tucson, p.395-397.

Schaller 0. 1999. Nomenclatura Anatômica Veterinária Ilustrada. Manole, São Paulo, SP. 614p.

Setchell B.P. 1978. The Mammalian Testis: the scrotum and thermoregulation. Cornell University Press, Ithaca, NY, p.90-108.

Silva A.E.D.F., Nunes J.F. \& Melo F.A. 1986. Influência da morfologia escrotal nas características do sêmen e seus efeitos na fertilidade de caprinos. Hora Vet. 5(29):66-69. 